\title{
Tópico e apêndice no português do Brasil: algumas considerações
}

\author{
Some notes on Topic and Appendix in Brazilian \\ Portuguese
}

\author{
Tommaso Raso \\ Andréa Ulisses \\ Universidade Federal de Minas Gerais
}

\begin{abstract}
This article, based on the Theory of Language in Act (CRESTI, 2000), analyses the informational unities of topic and comment apendix in a sample of three texts of Brazilian Portuguese: one dialogic text and two monologic texts. The goal is to show how these two units behave differently in the prosodic as in the distributional, morpho-syntactic and cognitive level. Their frequency in the two different types of interaction also shows different roles in the complexity of utterances, with different sensibility to different kinds of interaction. Our thesis is that they must be considered two different information unities and not the same unity in specular position.
\end{abstract}

Keywords

Informational structure; Informational patterning theory; Spontaneous speech.

\section{Resumo}

O artigo, com base na Teoria da Língua em Ato (CRESTI, 2000), analisa as unidades informacionais de tópico e de apêndice de comentário em uma amostra de três textos do português do Brasil: um texto dialógico e dois textos monológicos. O objetivo é mostrar 
como as duas unidades têm comportamentos diferentes tanto no nível prosódico quanto nos níveis distribucional, morfossintático e cognitivo. A frequiência delas nos diferentes tipos de textos mostra também diferentes papéis na complexização dos enunciados, com uma diferente sensibilidade ao tipo de interação. A tese é que se trata de unidades informacionais diferentes e não da mesma unidade em posição especular.

\section{Palavras-chave}

Estrutura informacional; Teoria da língua em ato; Fala espontânea. 


\section{Introdução}

$\mathrm{E}$

ste trabalho tem por objetivo mostrar alguns resultados da aplicação da

Teoria da Língua em Ato ${ }^{1}$ à fala espontânea do português do Brasil (PB)

quanto ao estudo da estrutura informacional do enunciado. Em particular se mostrarão algumas características das unidades informacionais de tópico (TOP) e de apêndice de comentário (APC), com especial aprofundamento para seus correlatos morfo-sintáticos, em uma amostra de três textos, por um total de 33 minutos e 32 segundos de fala espontânea. ${ }^{2}$ Os três textos pertencem ao domínio formal e foram gravados em cabine acústica. ${ }^{3} \mathrm{O}$ texto 1 (de 15,22 minutos e 2602 palavras, das quais 27 fragmentadas) é dialógico (os participantes distribuem a fala respectivamente em 150 e 149 turnos de duração equilibrada), enquanto os textos 2 e 3 (que são tratados juntos porque participantes e assunto não mudam) são prevalentemente monológicos (juntos somam 18,09 minutos e 2735 palavras, das quais 32 fragmentadas; os turnos são 70 por participante, sendo que alguns são extremamente longos e outros apenas confirmam a abertura do canal durante o monólogo do outro). Os participantes do texto 1 são um professor de Inglês e um aluno de escola pública de 14 anos; o assunto é o andamento das aulas de Inglês do aluno e a relação didática dele com sua professora. Os participantes dos textos 2 e 3 são duas professoras de escola pública: a entrevistadora é a coordenadora da escola, enquanto a entrevistada é a professora de Inglês. Os textos foram transcritos com o sistema Chat (MACWHINNEY, 1995 e http:// childes.psy.cmu.edu/), implementado para a notação prosódica (MONEGLIACRESTI, 1997); foram segmentados por enunciados e unidades tonais, ${ }^{4} \mathrm{e}$ etiquetados informacionalmente com base na Teoria da Língua em Ato, usando o software WinPitch de Philippe Martin (www.winpitch.com). 


\section{As unidades informacionais de tópico e de apêndice de comentário}

Na Teoria da Língua em Ato, a unidade informacional de TOPé definida funcionalmente como o âmbito de aplicação da força ilocucionária, que é veiculada pela unidade de comentário (COM). ${ }^{5}$ Constitui, portanto, a delimitação semântica do COM. Distribucionalmente, o TOP antecede sempre o COM. Entonacionalmente, configura-se como uma unidade de prefixo ( $t$ 'HART; COLLIER; COHEN, 1990), subordinada ao COM, e possui um foco entonacional.

A unidade de APC é definida funcionalmente como uma integração textual do COM. Distribucionalmente, segue sempre o COM. Entonacionalmente, configura-se como unidade de sufixo, subordinada ao COM, e não possui foco entonacional, mantendo sempre um perfil nivelado ou descendente. ${ }^{6}$

Nem o TOP nem o APC são interpretáveis em autonomia. Exemplos de estruturas TOP/COM e COM/APC são, pelo mesmo conteúdo locutivo, os enunciados das figuras 1 e $2 .^{7} \mathrm{O}$ mesmo enunciado poderia ser executado também através de uma única unidade de COM, a qual, por veicular a força ilocucionária e possuir interpretabilidade autônoma pragmaticamente, é a única unidade necessária e pode ser a única suficiente para a constituição de um enunciado. Esse último é identificável através de um perfil entonacional perceptível como terminal, e possui interpretabilidade pragmática. Essa interpretabilidade é conferida ao enunciado pela autonomia do COM. Quando o enunciado é realizado somente através do COM, sem a participação de outras unidades, é definido como enunciado simples. Quando é realizado através do $\mathrm{COM}$ e de uma ou mais outras unidades, ${ }^{8}$ é definido como complexo. Para os nossos fins, podemos considerar que cada unidade tonal realiza uma unidade informacional. $^{9}$ 


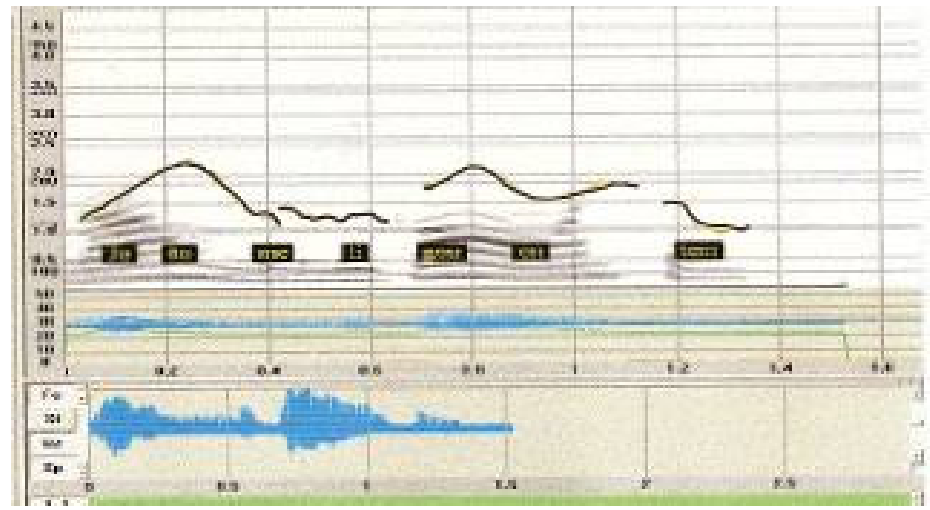

FIGURA 1: João/TOP me ligou ontem // $/$ COM

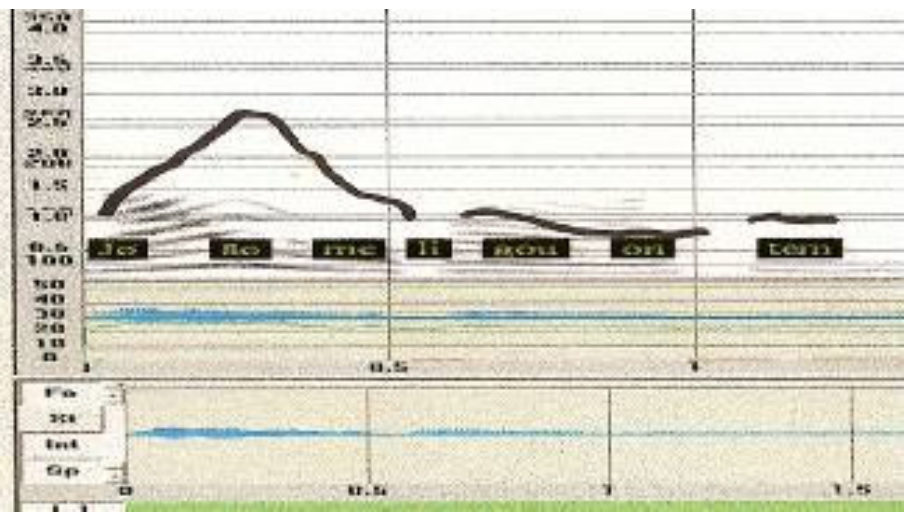

FIGURA 2: JOÃO/COM me ligou ontem $/ /^{\mathrm{APC}}$

Essas definições das duas unidades permitem um tratamento da informação muito diferente daquele de outras propostas presentes na literatura. ${ }^{10}$ Dois são os aspectos que interessam especificamente a este trabalho:

1. o fato de que uma unidade informacional se realiza independentemente da sua configuração sintática, mesmo se existem correlações estatisticamente mais frequientes de que outras;

2. o fato de que a unidade de TOP e a de APC devam ser consideradas como unidades informacionais diferentes e não como posicionamentos diferentes da mesma função informacional. 


\section{As unidades nos textos analisados}

Na nossa amostra foram individualizados 491 enunciados no texto 1 e 394 enunciados nos textos 2 e 3 . O maior número de enunciados por minuto no texto 1 (32,26 vs 21,61 nos texto 2 e 3) explica-se facilmente com a natureza dialógica desse texto e a natureza prevalentemente monológica dos outros dois. Pela mesma razão, temos uma proporção muito maior de enunciados simples no texto 1 do que nos textos 2 e 3 : no texto 1 temos 296 enunciados simples $(60,28 \%)$ e 195 complexos (39,72\%); nos textos 2 e 3 temos 186 enunciados simples $(47,05 \%)$ e 211 enunciados complexos $(62,95 \%) .{ }^{11}$ Uma outra medida que ajuda a interpretar a diferença dos dois tipos de interação é o número total de unidades tonais, que no texto 1 é de 930 e nos textos 2 e 3 é de 1026 . Esse dado mostra claramente como a uma quantidade maior de enunciados do texto 1 se contrapõe uma complexidade maior dos enunciados dos textos 2 e 3 . Essas diferenças são devidas a características próprias das interações com prevalência dialógica ou com prevalência monológica. Evidentemente, a prevalência dialógica facilita o acesso ao contexto, tornando menos importante contextualizar a ilocução através do recurso a outras unidades informacionais. A diferença na composição do enunciado entre os dois tipos de interação seria ainda mais evidente se excluíssemos as unidades informacionais de auxílio dialógico (AUX), que tem a função, entre outras, de sinalizar a tomada de turno, de verificar o canal ou de fazer algum tipo de pressão sobre o interlocutor. São, portanto, unidades ligadas imediatamente à interação e frequientes em situação dialógica. De fato, boa parte dos enunciados complexos de um texto dialógico é composta por uma unidade de COM associada a um AUX.

Focando agora as unidades, objeto principal do trabalho, foram individualizados 163 TOP seguros e 46 APC seguros no total. ${ }^{12}$ Entre os 163 TOP, 48 aparecem no texto 1 e 115 nos textos 2 e 3 . Entre os 46 APC, 25 pertencem ao texto I e 21 aos textos 2 e 3 . Os textos 2 e 3 mostram, portanto, bem mais do dobro de TOP do que o texto 1. Ao contrário, o número de APC não parece tão dependente da tipologia interacional, já que eles são até um pouco mais presentes no texto I, que, como já se disse, apresenta um menor número de enunciados complexos.

Essaé sem dúvida uma primeira diferença importante no comportamento das duas unidades, que nos permite dizer que o APC não contribui à complexificação informacional do texto com relação à sua tipologia interacional, enquanto o TOP parece ser um dos principais, se não o principal, responsáveis, pela complexificação 
informacional dos textos monológicos. O que queremos dizer é que, se nos textos monológicos aumenta muito a quantidade de enunciados complexos com relação aos textos dialógicos, isso não se deve a um aumento das unidades de APC (que não acontece), mas a um aumento das unidades de TOPs.

Essa afirmação seria reforçada se analisássemos as tipologias de TOPs, quanto à sua complexidade. ${ }^{13}$ No texto 1 , os TOPs são em grande parte simples, ${ }^{14}$ ou seja, não recursivos e sem apêndices de tópico (APT).${ }^{15}$ Ao contrário, nos textos 2 e 3 temos enunciados de até 4 TOPs $^{16}$ e uma quantidade de APTs enormemente superior: 6 APTs no texto 1 (concentrados em 3 enunciados) ${ }^{17} \mathrm{e}$ 44 APTs nos textos 2 e 3.

\section{Os correlatos morfossintáticos das unidades de TOP e APC}

Se olharmos para os correlatos morfossintáticos das duas unidades, notamos outras importantes diferenças. Seguem, nas tabelas 1 e 2, respectivamente, o quadro dos correlatos dos 163 TOP e o dos 46 APC.

TABELA 1

Correlatos morfossintáticos da unidade informacional de TOP

\begin{tabular}{l|rl}
\hline Sintagmas nominais com função de sujeito & $30=18,40 \%$ \\
Sintagmas nominais sem ligação sintáticas & $16=9,81 \%$ \\
Sintagmas nominais com função de objeto & $7=4,29 \%$ \\
Sintagmas preposicionais & $18=11,04 \%$ \\
Advérbio + sintagma nominal com função de sujeito & $2=1,22 \%$ \\
Advérbio + sintagma preposicional & $2=1,22 \%$ \\
Advérbio & $21=12,88 \%$ \\
Sintagma verbal com função de oração principal & $34=20,85 \%$ \\
(sem todas as regências) & \\
Sintagma verbal com função de sentença & $23=14,11 \%$ \\
(todas as regências preenchida na mesma unidade) & $10=6,13 \%$ \\
\hline Sintagma verbal com função de subordinada &
\end{tabular}

Pode-se notar que a maioria dos TOPs são realmente nominais, ${ }^{18}$ já que as várias formas nominais somam $45 \%$; mas também que estamos longe de ter unicamente formas nominais, já que temos $13 \%$ de advérbios sem formas 
nominais e, principalmente, mais de $41 \%$ de sintagmas verbais. Podemos notar também que a função de sujeito é a preferida, já que, entre os 53 SNs, 30, ou seja, quase $60 \%$, são sujeitos; ao contrário, é rara a função de objeto, com apenas 7 casos (13\%). Os restantes são SNs sem ligação sintática. Alguns exemplos desse último tipo são:

*GBL: eh / ${ }^{\mathrm{FAT}}$ por causa que /AUX ah / / ${ }^{\mathrm{FAT}}$ espanhol / ${ }^{\mathrm{TOP}}$ se você já [/] se você for lá na Espanha lá / ${ }^{\text {TOP }}$ cê já sabe comunicar // COM

*FBA: algumas aulas / ${ }^{\mathrm{TOP}}$ cê num consegue nada /^COM mesmo / ${ }^{\mathrm{COM}}$ né $/ /^{\mathrm{AUX}}$

Quanto aos SVs, é interessante notar que 57, ou seja, mais de 85\%, têm função de oração principal, enquanto somente menos de $15 \%$ têm função de oração subordinada. Mas é notável que mais de $34 \%$ dos sintagmas verbais são realizados como verdadeiras sentenças, isto é, com todas as valências preenchidas dentro da unidade de tópico. Inclusive, o alto número de tópicos sintagmas verbais e especialmente o alto número de tópicos sentenciais se caracteriza com muita probabilidade como uma particularidade do português do Brasil, já que essas porcentagens são claramente mais baixas nas outras línguas românicas estudadas (15,2\% no italiano). ${ }^{19}$ Alguns exemplos de tópicos sentenças são:

*VTR: cê estuda inglês / ${ }^{\text {TOP }}$ há quanto tempo // ${ }^{\text {COM }}$

*VTR: eu tava em sala / ${ }^{\text {TOP }}$ cê comentou comigo a diferença de inglês pra espanhol // COM

*GBL: / igual/AUX eu pego um texto/ ${ }^{\mathrm{TOP}}$ eu pego ele / ${ }^{\mathrm{TOP}}$ e traduzo ele todo //COM

*FBA: você tá [/] ele tá dentro da sala / ${ }^{\text {TOP }}$ mas somente o corpo hhh // ${ }^{\text {Com }}$

*FBA: cê dá um determinado tempo / TOP eles ainda / ${ }^{\wedge \mathrm{COM}}$ não são muito disciplinados // ${ }^{\mathrm{COM}}$

*GBL: porque / $\mathrm{AUX}$ você chegou numa escola nova / ${ }^{\mathrm{TOP}}$ outra realidade /COMel outros alunos / ${ }^{\mathrm{COMel}}$ outras necessidades // ${ }^{\mathrm{COMel}}$ 
TABELA 2

Correlatos morfossintáticos das unidades de APC

Sintagma nominal com função de sujeito

Sintagma nominal com função de objeto

Sintagma preposicional

Advérbio

Sintagma verbal com função de oração principal

Sintagma verbal com função de oração subordinada

Adjetivo

$$
\begin{aligned}
1 & =2,3 \% \\
4 & =8,7 \% \\
21 & =45,6 \# \\
9 & =19,5 \# \\
1 & =2,3 \% \\
9 & =19,5 \% \\
1 & =2,3 \%
\end{aligned}
$$

Os correlatos dos APCs se mostram muito diferentes daqueles dos TOPs. A maioria de APCs é também nominal, mas isso é devido a uma altíssima porcentagem de SP (quase 46\%). Entre os SNs a proporção entre sujeitos e objetos é invertida, com uma presença quádrupla dos objetos em comparação aos sujeitos. Isso também acontece comparando a proporção de SVs principais e subordinados: esses últimos chegam a quase $20 \%$ de todos os APCs, enquanto os principais aparecem com um único caso. Completa o quadro uma porcentagem de quase $20 \%$ de advérbios.

Olhando para os correlatos morfossintáticos devemos tirar duas conclusões:

1. que as unidades de TOP e APC se realizam independentemente de qualquer configuração sintática: em princípio não temos correlatos sintáticos inaceitáveis para uma unidade;

2. que existe uma diferença muito grande entre essas duas unidades: uma tende a hospedar em prevalência funções sintáticas de SN sujeito e de SV principal; a outra aceita só excepcionalmente essas funções e prefere claramente as opostas de SN objeto e de SV subordinado. Essas não são as únicas diferenças, como mostram as tabelas, mas são as mais gritantes.

\section{TOP e APC: duas unidades ou uma só?}

A diferença entre as duas unidades que chamamos de TOP e APC é questionada na literatura: ${ }^{20}$ os argumentos de quem questiona a diferença tendem a concluir que se trataria da mesma unidade informacional e que ela simplesmente pode aparecer em posição anteposta ou posposta à unidade de comentário. A 
diferença seria, portanto, somente de natureza distribucional e dessa diferença descenderiam as outras.

A discussão merece mais aprofundamentos e não pretendemos aqui chegar a conclusões definitivas. Mas um dos objetivos deste trabalho é, analisando o português do Brasil, levar alguns argumentos a favor do fato de que as duas unidades precisam ser interpretadas e estudadas como unidades distintas. Na seção 2 mostramos que as duas unidades se distinguem quanto aos perfis entonacionais, sendo que o TOP possui foco entonacional, enquanto o APC tem perfil nivelado ou descendente, sem foco. Na seção 3 notamos que a complexificação dos enunciados, típica da fala monológica, é devida em boa medida à unidade de TOP, enquanto a unidade de APC não joga papel algum com relação a isso. Na seção 4 mostramos que os correlatos morfossintáticos das duas unidades são claramente diferentes e, em certa medida, até opostos.

Cresti (2000 e 2003) e Tucci (2006) acrescentam alguns outros argumentos: o TOP teria modalidade e ponto de vista próprios, enquanto o APC sempre mantém a modalidade e o ponto de vista do COM; além disso, o TOP pode ser novo enquanto o APC pode ser somente dado. Na nossa amostra não estudamos a modalidade e o ponto de vista, mas verificamos que muitos TOPs servem para instaurar um novo âmbito de aplicação da força ilocucionária, enquanto isso nunca acontece, nem parece concebível, para oAPC. Ao contrário, todos os casos em que uma unidade aparentemente de apêndice parece instaurar um novo âmbito de aplicação da força ilocucionária resultam, a uma análise mais atenta, comentários ligados, ${ }^{21}$ com um movimento claro. ${ }^{22}$

Os argumentos de quem considera TOP e APC como uma unidade única são basicamente os seguintes:

1. ambas as unidades poderiam ser definidas como âmbito de aplicação da força ilocucionária;

2. os correlatos entonacionais e morfossintáticos diferentes se explicariam com a posição diferente.

O primeiro argumento parece funcionar com boa parte dos APCs, mas não com todos, enquanto a definição do APC como integração textual do COM funciona com todos os APCs. Alguns casos exemplares, em que não parece possível definir o APC como âmbito de aplicação da força ilocucionária, tirados da nossa amostra, são os seguintes: 
*GBL: ou então ${ }^{\mathrm{AUX}} /$ eu tentava \&t [/] sozinho / ${ }^{\mathrm{COM}}$ lá decifrar // ${ }^{\mathrm{APC}}$

*FBA: lógico que / ${ }^{\text {AUX }}$ uma coisa que não ficou ainda muito bem resolvida é a questão da / administração do tempo / ${ }^{\mathrm{COM}}$ né // ${ }^{\mathrm{AUX}}$ \&he / por causa / TOP deles / ${ }^{\text {COM }}$ mesmo // ${ }^{\text {APC }}$

*FBA: acabou o tempo / ${ }^{\mathrm{COM}}$ pronto acabou // ${ }^{\text {COMRelnec }}$ vamos corrigir // ${ }^{\mathrm{COM}}$ vamos fazer juntos / ${ }^{\mathrm{COM}}$ tal // ${ }^{\mathrm{APC}}$

*FBA: Olha / /NP a mudança / ${ }^{\mathrm{TOP}}$ foi [/] foi positiva / ${ }^{\mathrm{COM}} \operatorname{sim} /{ }^{\mathrm{APC}}$ né // ${ }^{\mathrm{FAT}}$

O segundo argumento atribui à posição um valor superior ao perfil entonacional e aos correlatos morfossintáticos (o que em si já seria discutível). Isso equivale a dizer que a posição gera uma realização entonacional e morfosintática diferente. Mas, mesmo aceitando essa afirmação, também não se explicaria tudo: por que o TOP permitiria a instauração de um novo âmbito da força ilocucionária e o APC não? Seria de novo efeito da posição? Mesmo nesse caso, deveríamos distinguir entre um TOP instaurativo, com potencialidades cognitivas de novidade, perfil entonacional com foco, correlatos morfossintáticos próprios, e responsável pela complexificação do enunciado ${ }^{23}$ e, por outro lado, um TOP não instaurativo (portanto de pura compilação ou, no máximo, desambiguante), com correlatos entonacionais e morfossintáticos diferentes, e não responsável pela complexificação do enunciado com relação ao tipo de interação. Anossa impressão é que, com todas essas diferenças, manter o mesmo nome para as duas unidades (ou para as duas realizações de uma suposta unidade única) geraria de fato a necessidade de distinguir entre duas subunidades, o que parece de fato repropor a distinção que se quer negar.

\section{Algumas considerações metodológicas}

Este trabalho se baseia numa metodologia relativamente nova e completamente desconhecida na literatura brasileira. O trabalho em si constitui um dos primeiros resultados publicados de um projeto grande, que está coletando e estudando um corpus do PB comparável com os corpora das quatro principais línguas românicas do projeto C-ORAL-ROM. Os corpora de italiano, espanhol, francês e português de Portugal já estão disponíveis para a comparação ${ }^{24}$. Mas o que torna metodologicamente extremamente original esse trabalho são dois 
aspectos. Por um lado, a imediata comparabilidade com quatro línguas que já possuem os textos coletados e segmentados com os mesmos critérios; considerando que as línguas são homogêneas geneticamente e ainda mais que uma delas é o português europeu, essa comparabilidade parece fundamental para muitos tipos de estudo. Por outro lado, é original a teoria que inspirou a arquitetura e, principalmente, a segmentação dos corpora. Isso não significa que eles não possam ser utilizados em outros quadros teóricos, mas que se abrem as portas para análises baseadas nos conceitos de enunciado e unidade tonal.

Graças a essa segmentação, podemos individualizar na fala unidades menores e estudar o comportamento delas dentro do discurso, observando o que parece ser próprio da fala e o que parece depender de cada língua. O conceito de enunciado é definido como a contraparte lingüística de um ato de fala, e identificado através de um perfil terminal perceptível pelo interlocutor. A entonação, portanto, nos fornece um instrumento para fazer a interface entre $o$ ato locutório e o ilocutório, dois conceitos teóricos interdependentes, mas até então não mensuráveis com um metro comum. O conceito de unidade tonal permite que a interface entonacional identifique também o conceito de unidade informacional dentro do enunciado, através de quebras perceptíveis como não terminais. Nessas bases, a fala pode ser analisada iuxta propria principia, graças a dispositivos próprios do canal e do meio.

Vale a pena marcar uma grande diferença que existe entre essa abordagem e as outras (diferentes também entre elas), tanto no estudo dos atos de fala quanto no estudo da estrutura informacional: a Teoria da Língua em Ato não é fruto da introspecção dos lingüistas, mas de uma lenta observação empírica de corpora constituídos no arco de quase trinta anos. Essa abordagem metodológica mostra como possa ser rico de frutos e de articulações teóricas o acúmulo de dados espontâneos e sua observação.

\section{Notas}

${ }^{1}$ Para uma exposição completa da teoria, veja-se Cresti (2000). Vários aprofundamentos da teoria quanto a aspectos específicos, entre os quais muitos daqueles citados neste trabalho, podem ser encontrados no sitio do laboratório Lablita da Universidade de Florença (http://lablita.dit.unifi.it/). Para uma versão reduzida da teoria em inglês, veja-se Cresti; Moneglia (2005). Para um resumo da teoria em português, veja-se Raso; Mello; de Deus; Jesus (2007). 
${ }^{2} \mathrm{O}$ estudo completo dessa amostra constituiu o piloto do projeto C-ORAL-BRASIL (www.c-oral-brasil.org) coordenado por T. Raso e H. Mello e parcialmente financiado pelo CNPq (400887/2007-0) e, principalmente, pela Fapemig (SHA-1627/06 e APQ-5958-5.06/07). O projeto se propõe a constituir a quinta ramificação do CORAL-ROM (CRESTI; MONEGLIA, 2005) que já disponibiliza corpora comparáveis das quatro principais línguas românicas européias. Os critérios de formação do corpus do PB no projeto C-ORAL-BRASIL são, portanto, idênticos aos do C-ORAL-ROM.

${ }^{3}$ Os textos e todos os dados do estudo podem ser acessados em Alves de Deus (2008) e Ulisses (2008).

${ }^{4}$ A fronteira de enunciado é marcada com barra dupla (//) ou com o signo (+) em caso de enunciados interrompidos. A fronteira entre unidades tonais é marcada com barra simples (/) ou com barra simples entre colchetes ([/]) quando se trata de retracting.

${ }^{5}$ A teoria toma como referência o conceito de ilocução de Austin (1962) e não o de Searle (1969). Para uma discussão sobre os motivos, veja-se Cresti (2002).

${ }^{6}$ Para aprofundamentos sobre essas unidades em análises baseadas em corpora vejam-se os textos seguintes (todos presentes no sítio http://lablita.dit.unifi.it/): Cresti; Firenzuoli (2002); Rossi (1999); Signorini (2004) e no prelo; Signorini; Firenzuoli (2003).

${ }^{7}$ Os exemplos são retirados de Raso; Mello; De Deus; Jesus (2007).

${ }^{8} \mathrm{Na}$ Teoria existem outras unidades, além do COM, do TOP e da APC, que não entram no escopo deste trabalho.

${ }^{9}$ Para a problematização dessa correspondência biunívoca, veja-se Cresti (2000, p. 148-162).

${ }^{10}$ Vejam-se pelo menos Halliday (1967), Givón (1984), Lambrecht (1994). Para o PB, Pontes (1987). É o caso de dizer que a Teoria da Língua em Ato é fruto de uma observação em corpora de fala espontânea que durou cerca de trinta anos; a metodologia empírica de base é, portanto, bem mais consistente do que aquela que funda as outras propostas de sistematização da estrutura informacional e dos enunciados no discurso.

${ }^{11} \mathrm{O}$ tipo de interação poderia ser invocado como causa de outras diferenças quantitativas que não nos interessam diretamente neste trabalho. Uma delas merece, todavia, uma menção: o texto 1 apresenta uma porcentagem de enunciados sem verbo bem maior do que os textos 2 e $3: 40,87 \%$ vs $31,27 \%$.

${ }^{12} \mathrm{O}$ número total deve, portanto, ser levemente maior, pois optamos por eliminar da contagem alguns casos em que o sinal acústico ou a interpretação funcional deixava alguma dúvida.

${ }^{13}$ Trata-se de observações importantes para a compreensão da estruturação do enunciado, mas que não podemos desenvolver adequadamente aqui e serão, 
portanto, ilustradas de maneira pontual em trabalho futuro.

${ }^{14}$ Menos de 30\% dos enunciados que contêm TOPs possuem um TOP complexo.

${ }^{15}$ Os APTs se definem funcionalmente como integração semântica da unidade de TOP; distribucionalmente seguem a unidade de TOP; entonacionalmente não possuem foco: as características dos possíveis perfis entonacionais dos APTs não foram adequadamente aprofundadas na teoria, mas uma primeira tentativa de descrição está em Ulisses (2008).

${ }^{16}$ Os TOPs complexos chegam a quase $45 \%$ dos enunciados com TOP.

${ }^{17}$ Os apenas 6 APTs do texto 1 , concentrados em 3 enunciados, são todos da fala do professor, o que mostra que, além da tipologia interacional, para a estruturação mais complexa do enunciado influi também o que podemos chamar de perícia de fala: o adolescente mostra de fato (nesse e em outros parâmetros) uma menor capacidade de estruração do enunciado.

${ }^{18}$ Muitos teóricos, entre os quais Lambrecht e Pontes citados, sustentam uma definição de TOP como exclusivamente nominal.

${ }^{19} \mathrm{Na}$ verdade, a impressão forte que se tem, depois do estudo dessa amostra e de observações não sistemáticas em outros textos, é que a porcentagem de TOPs em geral é bem mais alta no PB do que nas outras línguas românicas estudadas. Para quem olha a formação do PB com a lente da história de contato que essa língua viveu, trata-se de um aspecto que não surpreende. Vale a pena ressaltar que essa impressão, que ainda não pode ser demostrada pela insuficiência de dados estatisticamente relevantes, confirma, mesmo num quadro teórico completamente diferente, as intuições de Pontes (1987).

${ }^{20}$ Esse questionamento é facilitado pelas definições que são dadas dessas unidades; por isso, veja-se para um questionamento e uma argumentação internos à própria teoria, Lombardi Vallauri (no prelo).

${ }^{21}$ Para o conceito de comentário ligado (etiquetado ^ $\mathrm{COM}$ ), veja-se Cresti (2000, p. 160-163).

${ }^{22}$ Um caso muito interessante, e que merece ser estudado melhor, é o das perguntas parciais, quando a pergunta é realizada através de duas unidades, a primeira com a palavra QU e a segunda com o conteúdo da pergunta. Nesses casos, quando o conteúdo da pergunta é uma simples retomada textual, a pergunta parece ser realizada com uma unidade de COM e uma de APC, sem movimento nessa última unidade; quando, ao contrário, o conteúdo da pergunta introduz um elemento novo, esse elemento parece ser sempre caracterizado por um movimento que realiza um COM ligado.

${ }^{23}$ Um possível argumento de quem acha que TOP e APC devam ser consideradas como uma unidade única para justificar o fato de que o TOP é sensível ao tipo de 
interação (dialógico VS. monológico) enquanto o APC não teria essa sensibilidade poderia chamar em causa a menor ou maior ligação ao contexto situacional que distingue um diálogo de um monólogo: em situação dialógica, em que a interação é fortemente condicionada pela situação externa, não se teria muita necessidade de instaurar âmbitos de aplicação da força ilocucionária no discurso quanto numa atividade monológica, enquanto permaneceria invariada a necessidade de confirmar esse âmbito de aplicação em posição pós-comentário. Mas esse argumento indiretamente reforçaria a diferença de natureza cognitiva entre as duas unidades sem diminuir as diferenças empíricas que elas mostram quanto ao comportamento dentro do enunciado e dentro do processo discursivo.

${ }^{24}$ Veja-se Cresti; Moneglia (2005).

\section{Referências Bibliográficas}

ALVES DE DEUS, L. A unidade informacional de tópico no português do Brasil. 2008. Dissertação (Mestrado) - Faculdade de Letras da UFMG, Belo Horizonte, 2008.

AUSTIN, J. How to do things with words. Oxford: The Clarendon Press, 1962.

CRESTI, E. Corpus di italiano parlato. Firenze: Accademia della Crusca, 2000. v. I.

CRESTI, E. Modalità e illocuzione. In: BECCARIA, G. L.; MARELLO, C. (Org.). La parola al testo: scritti per Bice Mortara Garavelli. Alessandria: Dell'Orso, 2002. p. 144-153.

CRESTI, E. Modalité e illocution dans le topic e le comment. In: SCARANO, A. (Org.). Macro-syntaxe et pragmatique. L'analise linguistique de l'oral. Roma: Bulzoni, 2003. p. 133-180.

CRESTI, E.; FIRENZUOLI, V. L'articolazione informativa topic-comment e commentappendice: correlati intonativi. In: REGNICOLI, A. (Org.). La fonetica acustica come strumento di analisi della variazione linguistica in Italia. Atti delle XII Giornate del Gruppo di Fonetica Sperimentale. Roma: Il Calamo, 2002. p. 153-160.

CRESTI, E.; MONEGLIA, M. (Org.). C-ORAL-ROM. Integrated Reference Corpora for Spoken Romance Languages. Amsterdam-New York: Johns Benjamins, $2005+$ DVD.

GIVÓN, T. Syntax: A functional-typological introduction. Amsterdam: John Benjamins, 1984.

HALLIDAY, M. A. K. Notes on transitivity and theme in English. Journal of 
Linguistics, 3, p. 177-244, 1967.

t'HART, J.; COLLIER, R.; COHEN, A. A perceptual study on intonation. An experimental approach to speech melody. Cambridge: Cambridge University Press, 1990.

LAMBRECHT, K. Information structure and sentence form. Cambridge: Cambridge University Press, 1994.

LOMBARDI VALLAURI, E. Appendix or Postposed Topic: where does the difference lie? In: BANTI, G.; MEREU, L. (Org.). Atti delle Giornate Internazionali sulla Struttura dell'Informazione. Roma, giugno 2006. (No prelo).

MAC WHINNEY, B. The CHILDES Project: tools for analizing talk. Hillsdale, NJ: Lawrence Erlbaum Associates, 1995.

MONEGLIA-CRESTI. Intonazione e criteri di trascrizione del parlato. In: BORTOLINI, U., PIZZUTO, E. (Org.). Il progetto CHILDES Italia. Pisa: Del Cerro, 1997.

PONTES, E. O tópico no português do Brasil. Campinas: Pontes, 1987.

RASO, T.; MELLO. H.; JESUS, A. U.; DE DEUS, L. A. A primeira aplicação da Teoria da Língua em Ato ao PB. Revista de Estudos da Linguagem, v. 15, n. 2, p. 147-166, 2007.

ROSSI, F. Non lo sai che ora è? Alcune considerazioni sull'intonazione e sul valore pragmatico degli enunciati con dislocazione a destra. Studi di grammatica italiana, XVIII, p. 144-193, 1999.

SEARLE, J. Speech Acts. Cambridge: Cambridge Univerity Press, 1969.

SIGNORINI S. L'unità di topic caratteristiche e frequenza in un corpus di italiano parlato. Il topic complesso In: D' ACHILLE, P. (Org.). Generi, architetture e forme testuali. Atti del VII convegno internazionale SILFI. Roma, 1-5 ottobre 2002. Firenze: Franco Cesati, 2004. p. 227-238.

SIGNORINI, S. Il topic: criteri di identificazione e correlati morfosintattici in un corpus di italiano Parlato. In: Atti del convegno "Il parlato italiano". (No prelo.)

SIGNORINI, S. - FIRENZUOLI, V. L'unitá informativa di Topic: correlati intonativi. Em: Marotta, G. - Nocchi, N. Atti delle XIII Giornate del Gruppo di Fonetica Sperimentale (A.I.A.). Pisa: E.T.S., 2003. p. 177-184.

TUCCI, I. L'espressione lessicale nella modalità del parlato spontaneo. Analisi del corpus C-ORAL-ROM italiano. Tese (Doutorado) - Università degli Studi di Firenze, 2006.

ULISSES, A. As unidades de apêndice no português do Brasil. Dissertação (Mestrado) - Faculdade de Letras da UFMG, Belo Horizonte, 2008. 